\title{
Longitudinal impact of oral health on geriatric syndromes and clinical outcomes in community-dwelling older adults
}

\author{
Jihye Lim', Hyungchul Park², Heayon Lee ${ }^{3}$, Eunju Lee ${ }^{4}$, Danbi Lee ${ }^{1}$, Hee-Won Jung ${ }^{4^{*}}$ and I-Young Jang ${ }^{4,5^{*}}$
}

\begin{abstract}
Background: Oral health is essential for daily living and plays a pivotal role in overall health conditions and wellbeing. This study evaluated the impact of self-reported oral health on geriatric conditions, institutionalization, and mortality.

Methods: This study analyzed the population of the Aging Study of Pyeongchang Rural Area that had undergone geriatric assessments between 2016 and 2017. The oral health status of the participants was determined using three items from the General Oral Health Assessment Index, and the participants were classified into three groups according to the total sum of the scores as good (3), fair (4-7), or poor (8-15). The outcomes were the incidence of geriatric syndromes at 2 years and the composite outcome of mortality and institutionalization.

Results: Among the 1189 participants, $44.1 \%$ were women, and the mean age of the study population was 75.0 years. Good, fair, and poor oral health were observed in 597 (50.2\%), 406 (34.1\%), and 186 (15.6\%) individuals, respectively. Worsening oral health status was associated with the incidences of various geriatric syndromes at follow-up, and these associations were attenuated after adjusting for baseline demographic and geriatric parameters. Similarly, the significant association between baseline oral health status and the incidence of the composite outcome was attenuated after adjusting for demographic and geriatric parameters.

Conclusions: Oral health affected the geriatric health conditions in this prospective, longitudinal cohort of community-dwelling older adults. The correlations and interactions of oral health status with other functional parameters may deserve consideration as a geriatric domain.
\end{abstract}

Keywords: Oral health, Frailty, Geriatrics

\section{Background}

Oral health is one of the most important domains of overall health among these charges in essential daily functions including nutritional intake and speaking. It also affects social interaction, mood, productivity, and self-esteem [1]. An estimated 3.5 billion people worldwide have dental problems, according to the 2017 Global

\footnotetext{
*Correspondence: dr.ecsta@gmail.com; onezero2@gmail.com

${ }^{4}$ Division of Geriatrics, Department of Internal Medicine, Asan Medical Center, University of Ulsan College of Medicine, 88 Olympic-ro 43-gil, Songpa-gu, Seoul, Republic of Korea

Full list of author information is available at the end of the article
}

Burden of Disease Study [2]. Oral health includes proper oral function without oral diseases such as edentulism, caries, xerostomia, and periodontal disease, assuring people to perform well on the aspects of physical, mental, and social functions without discomfort, pain, or embarrassment [3].

In older adults, factors such as cognitive impairment, decreased mobility, and limited socioeconomic resources may preclude receiving proper dental or medical care for oral health problems $[1,4,5]$. Furthermore, older adults with multiple comorbidities or polypharmacy are often

(c) The Author(s). 2021 Open Access This article is licensed under a Creative Commons Attribution 4.0 International License, which permits use, sharing, adaptation, distribution and reproduction in any medium or format, as long as you give appropriate credit to the original author(s) and the source, provide a link to the Creative Commons licence, and indicate if changes were made. The images or other third party material in this article are included in the article's Creative Commons licence, unless indicated otherwise in a credit line to the material. If material is not included in the article's Creative Commons licence and your intended use is not permitted by statutory regulation or exceeds the permitted use, you will need to obtain permission directly from the copyright holder. To view a copy of this licence, visit http://creativecommons.org/licenses/by/4.0/. The Creative Commons Public Domain Dedication waiver (http://creativecommons.org/publicdomain/zero/1.0/) applies to the data made available in this article, unless otherwise stated in a credit line to the data. 
restricted in receiving dental care due to concerns regarding procedure-related adverse outcomes [3]. Consequently, older individuals tend to use less dental services, resulting in the accumulation of untreated oral health problems that may consequently lead to a reduced quality of life and poorer nutritional status.

Previous cross-sectional and longitudinal studies showed that oral health status, as assessed according to the number of teeth, tongue pressure, or diverse questionnaires, is associated with frailty in older adults [6-9]. Frailty, defined as decreased physiological reserve and increased vulnerability to possible stressors, is associated with adverse health outcomes including falls, functional decline, higher healthcare use, and increased mortality in older adults $[10,11]$. As oral health status can affect systemic inflammation and nutritional status that are also major mechanisms in the progression of frailty and functional decline, oral problems might be an important clinical issue among the geriatric domains in clinical care for older adults [12].

In the public health setting, studies suggested that overall health status including frailty can be improved by multicomponent intervention programs targeting physical performance, nutritional status, and geriatric functional domains [13-15]. However, less is known regarding the in-depth roles of oral health status on various geriatric domains and health outcomes over time, beyond the effects on nutritional status. Therefore, we used a three-item questionnaire to evaluate self-reported oral health to evaluate the associations between selfreported oral health and comprehensive geriatric syndromes to determine their longitudinal impacts on geriatric conditions and overall health outcomes including institutionalization and mortality in resource-limited public healthcare settings.

\section{Methods}

\section{Study population}

We analyzed records from the Aging Study of Pyeongchang Rural Area (ASPRA), a prospective populationbased cohort focusing on frailty and geriatric syndromes of older, community-dwelling adults. The detailed design and baseline population characteristics of the ASPRA have been described previously [16]. The inclusion criteria for the study were (1) age $\geq 65$ years; (2) enrolled in the National Healthcare Service and receiving public healthcare services; (3) self-ambulatory with or without assistive devices; (4) currently residing at home; and (5) able to provide informed consent either by themselves or by their family members. Individuals who were institutionalized or bed-ridden requiring nursing home-level care at home were excluded at the time of enrollment.

After the initial establishment of the study protocol in 2014, the study population was expanded to other areas in Pyeongchang county. Thus, this study included the records of 1,189 participants who had undergone baseline evaluations between 2016 and 2017. The cohort study was approved by the Institutional Review Board of Asan Medical Center, Seoul, Korea (Identification number: 2015 -0673), and all participants provided written informed consent.

\section{Assessment of oral health status}

We adopted a three-item questionnaire from the General Oral Health Assessment Index scale to assess oral health status [8]. The three questionnaire items were (1) "How often do you have problems in speaking clearly because of the status of your teeth or dentures" (assessment of physical function); (2) "How often do you limit the kinds or amounts of food you eat due to problems with your teeth or dentures" (assessment of pain or discomfort); and (3) "How often do you limit contact with people due to the condition of your teeth or dentures" (assessment of the psychosocial aspects of oral health) [8]. These items were scored with five grades ranging from 1 to 5 points, with higher scores indicating worse conditions. Based on a combined score ranging from 3 to 15 points, we established three oral health status groups: good (3 points), fair (4-7 points), and poor (815 points), considering the distributions of scores as shown below. We also assessed whether the participants were using removable dentures and assessed their sidedness (maxilla, mandible, or both) and functioning.

\section{Geriatric parameters}

Trained nurses performed the comprehensive geriatric assessments (CGAs). Medical problems were assessed and multimorbidity was defined as having two or more of 11 diseases including diabetes, hypertension, asthma, chronic kidney disease, malignancy, chronic lung disease, myocardial infarction, angina, heart failure, stroke, and arthralgia [16]. We also counted the number of medications, with polypharmacy defined as the regular use of more than five medications. Activities of daily living (ADLs) for seven items including continence, bathing, dressing, toileting, transferring, eating, and washing of the hands and face, as well as instrumental activities of daily living (IADL) for 10 items including household chores, food preparation, going out a short distance, handling finances, grooming, laundry, shopping, transportation, managing own medications, and using the telephone, were assessed. The need for assistance for one or more items was considered a disability in ADL or IADL [17]. Cognitive status was assessed by the Korean version of the Mini-Mental State Examination, with cognitive dysfunction defined as scores of <24 [18]. We used the Korean version of the Center for Epidemiological Studies depression scale to assess mood, with 
scores $>20$ indicating the presence of depressive mood [19]. Nutritional status was assessed using the MiniNutritional Assessment-Short Form, with scores $\leq 11$ indicating malnutrition [20]. Physical performance was assessed by the Short Physical Performance Battery (SPPB) to evaluate standing balance, walking speed, and five-time chair rise tests. The SPPB was scored from 0 to 12 , with higher scores indicating better levels of function. We defined an SPPB total score of $\leq 9$ as poor physical performance [21]. Muscle mass was measured by bioelectrical impedance analysis (InBody 620; InBody, Seoul, Republic of Korea), at 5, 50, and $500 \mathrm{kHz}$. Skeletal muscle index (SMI) was calculated as the appendicular skeletal muscle mass divided by the height ${ }^{2}$, with low muscle mass defined as SMI $<7.0 \mathrm{~kg} / \mathrm{m}^{2}$ for men and < $5.7 \mathrm{~kg} / \mathrm{m}^{2}$ for women [22]. Underweight was defined as a body mass index of $\leq 18.5 \mathrm{~kg} / \mathrm{m}^{2}$.

Frailty status was assessed by the Cardiovascular Health Study frailty phenotype criteria [23, 24]. The frailty phenotype evaluated five domains: (1) exhaustion (poor endurance, a feeling that everything is an effort or moderate inability to get going for most of the time during the last week) [16]; (2) low activity level (lowest 20th percentile of physical activity according to the Korean version of the International Physical Activity Questionnaires Short Form [25]); (3) slowness (usual gait speed < $0.8 \mathrm{~m} / \mathrm{s}$ in the 4-m walking test); (4) weakness (dominant hand grip strength $<26 \mathrm{~kg}$ for men and $<17 \mathrm{~kg}$ for women); and (5) weight loss (unintentional weight loss > $3 \mathrm{~kg}$ in the past 6 months) [26]. The number of positive items was scored and categorized as robust ( 0 points), prefrail (1-2 points), or frail (3-5 points).

\section{Outcome measures}

The primary outcome measures were incidence of abnormality or impairment in development of disability in ADL or IADL, depressive mood, cognitive impairment, frailty, and low physical performance according to baseline oral health status in population of no baseline abnormality in specific domains, These outcomes were assessed annually with similar CGA components as in the baseline examination.

The secondary outcome was the composite of mortality and institutionalization to long-term care facilities due to functional decline, as reported by telephone interviews with participants and family members every 3 months until August 2020.

\section{Statistical analyses}

We used one-way analysis of variance to assess differences in clinical parameters among the three oral health score groups. To assess the dose-response effects of oral health status on clinical parameters, we used linear regression analysis to calculate $P$-values for trends for categorical variables and Mann-Whitney or t-tests for continuous variables. To identify the associations between baseline oral health status and primary outcome at 2 years, we used logistic regression analysis to calculate the odds ratios. Analysis on incidence of the primary outcome measures were performed in population with no abnormality for each measure. To assess the associations between baseline oral health status and the secondary, composite outcome, we used Kaplan-Meier curves with log-rank tests and Cox regression analysis with hazard ratios. Two-sided $P$ values $<0.05$ were considered statistically significant. The statistical analyses were performed using $\mathrm{R}$ (version 3.6.0, https://www.r-project.org).

\section{Results}

\section{Characteristics of the study population}

The mean age of the study population was $75.0 \pm 6.2$ years, and $44.1 \%$ (524 of 1189 ) were women. The baseline characteristics of the participants are shown in Table 1. Good, fair, and poor oral health were reported by 597 (50.2\%), 406 (34.1\%), and $186(15.6 \%)$ of individuals. Individuals with poor oral health were more likely to be older; with low socioeconomic status; higher multimorbidity, polypharmacy, cognitive dysfunction, depression, dismobility, malnutrition, sarcopenia, and $\mathrm{ADL} / \mathrm{IADL}$ disability; and have fall history in the past year (Table 1).

Physical difficulties when speaking were reported by 295 (24.9\%, item 1) individuals, while 544 felt discomfort when eating in ( $45.8 \%$, item 2$)$ and 58 reported psychosocial distress when in contact with others $(4.9 \%$, item 3), as shown in Additional file 1, Supplementary Table 1. The mean and standard deviation of the thee item-based total score was $5.1 \pm 2.7$.

A total of $52.2 \%$ (621 of 1189) of participants used removable dental prosthesis, among whom 81.3\% (505/ 621) used both-sided dentures. Among participants not currently using prostheses, $15.7 \%$ (89/568) needed dentures, while $8.2 \%(51 / 621)$ of prosthesis users felt that dentures were unnecessary. The participants using bothsided dentures showed the highest overall scores for the questionnaire, followed by one-sided denture users and non-denture users in Supplementary Table $2(5.7 \pm 2.9$ vs. $5.1 \pm 2.6$ vs. $4.6 \pm 2.5, P<0.001)$.

\section{Impacts of self-reported oral health on common geriatric conditions at 2 year}

Poor oral health was associated with the deterioration of geriatric conditions and frailty. We evaluated the new occurrence of each variable during the 2 years of followup among the participants who did not have each geriatric syndrome at baseline. As shown in Table 2, baseline poor oral health was associated with increased risks of 
Table 1 Baseline characteristics according to self-reported oral health

\begin{tabular}{|c|c|c|c|c|c|}
\hline Variables & $\begin{array}{l}\text { Good }^{\mathrm{a}} \\
(N=597)\end{array}$ & $\begin{array}{l}\text { Fair }^{\mathrm{a}} \\
(N=406)\end{array}$ & $\begin{array}{l}\text { Poor }^{a} \\
(N=186)\end{array}$ & $P$-value & $P$-for trend \\
\hline Gender (men) & $255(42.7 \%)$ & $200(49.3 \%)$ & 69 (37.1\%) & 0.014 & 0.699 \\
\hline Age (years) & $73.6 \pm 5.9$ & $75.8 \pm 6.0$ & $78.0 \pm 6.1$ & $<0.001$ & $<0.001$ \\
\hline Living alone & $144(24.1 \%)$ & $130(32.0 \%)$ & $63(33.9 \%)$ & 0.005 & 0.002 \\
\hline Education level (years) & $6.6 \pm 4.0$ & $5.8 \pm 3.5$ & $4.9 \pm 3.1$ & $<0.001$ & $<0.001$ \\
\hline Medical aid(monthly income < USD 500) & $33(5.5 \%)$ & $35(8.6 \%)$ & $22(11.8 \%)$ & 0.011 & 0.003 \\
\hline $\mathrm{BMI}\left(\mathrm{kg} / \mathrm{m}^{2}\right)$ & $25.0 \pm 3.3$ & $24.7 \pm 3.7$ & $24.8 \pm 3.2$ & 0.184 & 0.184 \\
\hline Multimorbidity & $284(47.6 \%)$ & $213(52.5 \%)$ & $118(63.4 \%)$ & 0.001 & $<0.001$ \\
\hline Hypertension & $336(56.3 \%)$ & $238(58.6 \%)$ & $123(66.1 \%)$ & 0.059 & \\
\hline Arthralgia & $268(44.9 \%)$ & $201(49.5 \%)$ & $113(60.8 \%)$ & 0.001 & \\
\hline Diabetes & $111(18.6 \%)$ & $73(18.0 \%)$ & $55(29.6 \%)$ & 0.002 & \\
\hline Heart failure & $37(6.2 \%)$ & $24(5.9 \%)$ & $17(9.1 \%)$ & 0.297 & \\
\hline Malignancy & $28(4.7 \%)$ & $25(6.2 \%)$ & $13(7.0 \%)$ & 0.394 & \\
\hline Polypharmacy & $113(18.9 \%)$ & $93(22.9 \%)$ & $64(34.4 \%)$ & $<0.001$ & $<0.001$ \\
\hline Cognitive dysfunction by MMSE & $170(28.5 \%)$ & $148(36.5 \%)$ & $101(54.3 \%)$ & $<0.001$ & $<0.001$ \\
\hline Depression by CES-D & $298(49.9 \%)$ & $248(61.1 \%)$ & $146(78.5 \%)$ & $<0.001$ & $<0.001$ \\
\hline SPPB score & $8.7 \pm 2.4$ & $8.3 \pm 2.4$ & $7.2 \pm 2.7$ & $<0.001$ & $<0.001$ \\
\hline Malnutrition by MNA-SF & $158(26.5 \%)$ & $142(35.0 \%)$ & $92(49.5 \%)$ & $<0.001$ & $<0.001$ \\
\hline $\mathrm{SMI}\left(\mathrm{kg} / \mathrm{m}^{2}\right)$ & $16.1 \pm 3.9$ & $15.8 \pm 4.3$ & $14.6 \pm 3.9$ & $<0.001$ & $<0.001$ \\
\hline Frailty status by $\mathrm{CHS}$ & & & & $<0.001$ & $<0.001$ \\
\hline Robust & $108(18.1 \%)$ & $58(14.3 \%)$ & $17(9.1 \%)$ & & \\
\hline Prefrail & $401(67.2 \%)$ & $259(63.8 \%)$ & $109(58.6 \%)$ & & \\
\hline Frail & $88(14.7 \%)$ & $89(21.9 \%)$ & $60(32.3 \%)$ & & \\
\hline ADL disability & $75(12.6 \%)$ & $86(21.2 \%)$ & $52(28.0 \%)$ & $<0.001$ & $<0.001$ \\
\hline IADL disability & 119 (19.9\%) & 121 (29.8\%) & 77 (41.4\%) & $<0.001$ & $<0.001$ \\
\hline Fall in the past year & $102(17.1 \%)$ & $93(22.9 \%)$ & 56 (30.1\%) & $<0.001$ & $<0.001$ \\
\hline
\end{tabular}

Data presented as means \pm standard deviations or numbers (\%)

${ }^{a}$ According to the oral health item score, the groups were defined as good (3), fair (4-7), and poor (8-15)

$A D L$ activities of daily living; BMI body mass index; CES-D Center for Epidemiologic Studies-Depression; CHS Cardiovascular Health Study; IADL Instrumental

Activities of Daily Living; MMSE Mini-Mental State Examination; MNA-SF Mini Nutritional Assessment-Short Form; SMI Skeletal Muscle Index; SPPB Short Physical

Performance Battery

developing cognitive dysfunction, depression, low physical performance, disability (ADL or IADL), and frailty (Table 2). However, after controlling for demographic and geriatric parameters no significant association could be shown.

\section{The composite outcome of mortality and} institutionalization and oral health

During the median follow-up of 40 months (range, 3547), 50 individuals were institutionalized and 52 died. The overall probability of the composite outcome comprising institutionalization or mortality according to selfreported oral perception is shown in Fig. 1. People with good oral health had a better composite outcome compared to that for individuals with fair or poor oral health (good vs. fair vs. poor; $96.6 \%$ vs. $94.8 \%$ vs. $95.2 \%$ at 1 year and $72.9 \%$ vs. $76.8 \%$ vs. $65.6 \%$ at 3 years; log-rank
$P<0.001)$. In an unadjusted Cox regression analysis, worsening self-reported oral perception was significantly associated with the incidence of the composite outcome (Table 3). After adjusting for age, gender, and baseline geriatric parameters, the correlation between baseline oral health and the composite outcome was attenuated.

\section{Discussion}

In this prospective cohort study of older participants representing the general rural population of Korea, a worsening self-reported state of oral health was associated with deteriorating geriatric clinical parameters at 2 years and adversely affected the composite outcome of death and institutionalization. However, these associations were attenuated after adjusting for demographic and geriatric parameters. While most previous studies assessed oral health status as a predictor of future undernutrition in 
Table 2 Oral health status and incidence of geriatric syndromes at 2 years (logistic regression analysis)

\begin{tabular}{|c|c|c|c|}
\hline & Model 1 & Model 2 & Model 3 \\
\hline & OR (95 \% Cl) & OR (95 \% Cl) & OR $(95 \% \mathrm{Cl})$ \\
\hline \multicolumn{4}{|c|}{ Underweight } \\
\hline Good & Reference & Reference & Reference \\
\hline Fair & $0.74(0.18-2.96)$ & $0.57(0.14-2.33)$ & $0.51(0.13-2.00)$ \\
\hline Poor & $2.18(0.61-7.8)$ & $1.47(0.38-5.67)$ & $1.54(0.44-5.43)$ \\
\hline \multicolumn{4}{|c|}{ Low muscle mass } \\
\hline Good & Reference & Reference & Reference \\
\hline Fair & $1.41(0.72-2.76)$ & $1.52(0.74-3.14)$ & $0.91(0.56-1.48)$ \\
\hline Poor & $1.78(0.79-4.03)$ & $1.02(0.41-2.53)$ & $1.26(0.71-2.22)$ \\
\hline \multicolumn{4}{|c|}{ Cognitive dysfunction } \\
\hline Good & Reference & Reference & Reference \\
\hline Fair & $1.06(0.68-1.64)$ & $0.99(0.62-1.58)$ & $1.00(0.73-1.39)$ \\
\hline Poor & $2.10(1.23-3.60)$ & $1.36(0.76-2.45)$ & $1.45(0.98-2.14)$ \\
\hline \multicolumn{4}{|c|}{ Depression } \\
\hline Good & Reference & Reference & Reference \\
\hline Fair & $2.06(1.19-3.57)$ & $2.11(1.20-3.71)$ & $1.40(0.89-2.22)$ \\
\hline Poor & $3.11(1.66-5.85)$ & $2.68(1.39-5.19)$ & $1.77(1.04-2.99)$ \\
\hline \multicolumn{4}{|c|}{ Low physical performance } \\
\hline Good & Reference & Reference & Reference \\
\hline Fair & $1.42(1.01-2.01)$ & $1.23(0.85-1.79)$ & $1.08(0.85-1.39)$ \\
\hline Poor & $2.23(1.31-3.79)$ & $1.55(0.88-2.72)$ & $1.20(0.86-1.68)$ \\
\hline \multicolumn{4}{|c|}{ Disability } \\
\hline Good & Reference & Reference & Reference \\
\hline Fair & $1.17(0.81-1.69)$ & $1.15(0.78-1.69)$ & $0.96(0.74-1.25)$ \\
\hline Poor & $1.79(1.06-3.03)$ & $1.50(0.86-2.61)$ & $1.16(0.83-1.63)$ \\
\hline \multicolumn{4}{|c|}{ Multimorbidity } \\
\hline Good & Reference & Reference & Reference \\
\hline Fair & $0.88(0.51-1.54)$ & $0.91(0.51-1.62)$ & $0.80(0.56-1.13)$ \\
\hline Poor & $1.00(0.46-2.17)$ & $0.84(0.37-1.88)$ & $0.83(0.51-1.37)$ \\
\hline \multicolumn{4}{|l|}{ Frailty } \\
\hline Good & Reference & Reference & Reference \\
\hline Fair & $1.49(1.19-1.87)$ & $1.24(0.97-1.59)$ & $1.27(0.92-1.76)$ \\
\hline Poor & $3.20(2.46-4.17)$ & $2.08(1.55-2.78)$ & $1.40(0.95-2.07)$ \\
\hline
\end{tabular}

Model 1: unadjusted analysis

Model 2: adjusted for age and gender

Model 3: adjusted for age, gender, baseline medical aid, multimorbidity, polypharmacy, cognitive dysfunction, depression, low physical performance, ADL or IADL disability, and low muscle mass

$\mathrm{Cl}$ confidence interval; $O R$ odds ratio

older adults, this study comprehensively evaluated the interaction between oral health status at baseline and for future geriatric functional parameters.

In our study, individuals with poor self-reported oral health were more likely to be malnourished and sarcopenic, consistent with literature supporting the importance of oral health parameters such as the number of teeth, salivary secretion, and masticatory ability in maintaining essential daily nutrition [27]. Individuals with poor oral health have difficulty in chewing vegetables, fruit, and meat [7] and thus, may consume comparatively easy-toswallow but less nutritious food such as mashed or blended foods with high sugar or fat content $[1,9,28,29]$. Moreover, in our study, participants with poor oral health had a higher rate of baseline multimorbidity, consistent with previous studies supporting the association of poor oral condition with systemic diseases including diabetes, cardiovascular disease, pulmonary infection, kidney disease, and even dementia [30-34]. Possible explanations for these associations include systemic inflammatory responses due to periodontitis or oral abscess causing comorbidity, and the fact that oral disease and comorbidities share risk factors such as alcohol, smoking, and unhealthy diet [35]. Unsatisfactory oral health also can adversely affect mood, as observed in the present study. Individuals tend to be socially withdrawn when feeling embarrassed to eat or communicate with others due to inaccurate pronunciation or aesthetic appearance from a lack of teeth [36]. These factors may negatively affect mental health, lower self-esteem, and cause depression [36, 37].

In addition to these cross-sectional associations of oral health and geriatric parameters, we also observed the longitudinal impacts of baseline oral health on the future incidence of geriatric syndromes and composite outcome, although the impacts of oral health status on the incidences of the clinical outcomes were attenuated by including baseline geriatric parameters. Frailty, a clinically recognizable state of vulnerability with decreased physiological reserve occurring with human aging, is associated with falls, disabilities, treatment-related adverse outcomes, and even mortality [38]. The risk factors for frailty and frailty progression include sociodemographic, physical, biological, psychological, and lifestyle factors [39, 40]. Previous studies revealed the impact of oral health on physical (weight and muscle loss, disability, and mobility), biological (inflammation), psychological (depression and cognition), and lifestyle (food intake) factors [41-44]. Our results also showed the relationship between oral and general health. With previously reported evidence suggesting frailty as an aging phenomenon correlated with global functional parameters [16, 45], these various conditions may lead to longitudinal deterioration of frailty, resulting multifaceted deterioration across geriatric parameters.

We used three self-reported items to evaluate oral health. In resource-limited, real-world clinical practices, the use of comprehensive oral health assessments might be less feasible. We selected these three items to reflect the various facets of oral health including physical function in speaking (item 1), pain and discomfort (item 2), and psychosocial/psychological aspects (item 3) [8]. 


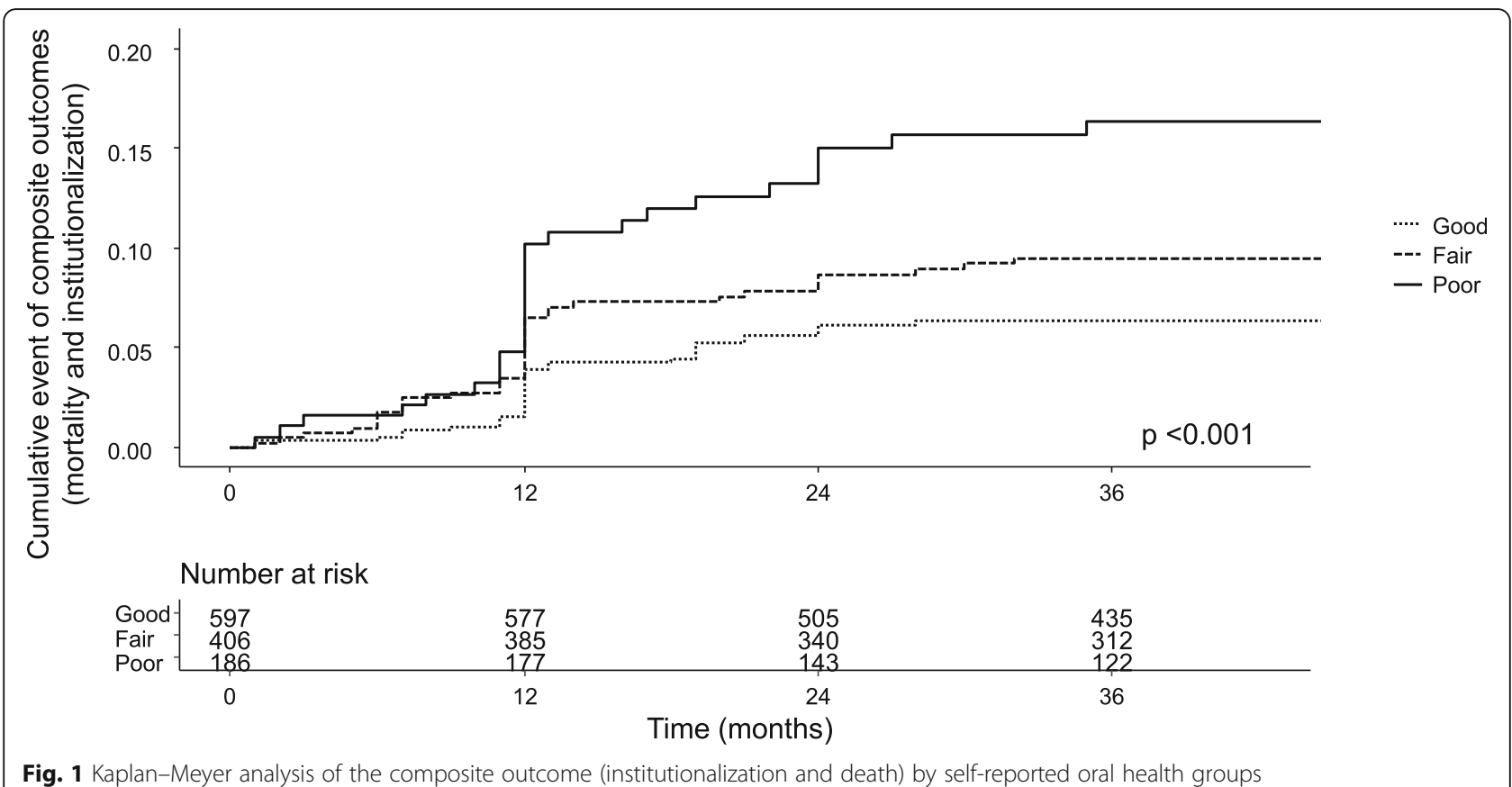

These limited items captured the cross-sectional correlations and longitudinal clinical relevance of baseline oral health status. It would be beneficial to do brief oral assessments in caring for geriatric populations.

Recent reports indicate that frailty and geriatric syndromes can be managed even in resource-scarce rural communities through the applicate of multicomponent intervention programs including exercise; nutrition; and geriatric management of potentially inappropriate medications, chronic diseases, cognitive- and mood problems $[46,47]$. The combination of the observations from the present study with those of previous reports allows the future assessment of the beneficial effects of community-based programs targeting older populations to improve oral health status on frailty and geriatric outcomes on top of dental health status per se.

Our study has some limitations. First, our study population was limited to a rural country of South Korea.

Table 3 Oral health status and institutionalization or death by Cox regression analysis

\begin{tabular}{llll}
\hline & Model 1 & Model 2 & Model 3 \\
& OR $(\mathbf{9 5} \% \mathrm{Cl})$ & OR $(\mathbf{9 5} \% \mathrm{Cl})$ & OR $\mathbf{9 5} \% \mathrm{Cl})$ \\
\hline Good & Reference & Reference & Reference \\
Fair & $1.53(0.97-2.42)$ & $1.12(0.71-1.78)$ & $0.99(0.62-1.58)$ \\
Poor & $2.68(1.64-4.37)$ & $1.52(0.92-2.53)$ & $1.19(0.71-2.00)$
\end{tabular}

Model 1: unadjusted analysis

Model 2: adjusted for age and gender

Model 3: adjusted for baseline medical aid, multimorbidity, polypharmacy, cognitive dysfunction, depression, low physical performance, ADL or IADL disability, and low muscle mass

$\mathrm{Cl}$ confidence interval; $O R$ odds ratio
Therefore, our results may not be generalized to other regions and ethnicities, although previous reports from the same population showed comparable characteristics to those in Korean rural-dwelling older populations [16]. Second, medically objective oral health evaluations were not performed. Further studies are warranted that include physician-assessed oral health, with some interventional attempts to assess the possible protective effects of dental care in older populations to improve geriatric outcomes. Third, while the statistical associations between oral health status and incidence of geriatric syndromes or the composite outcome were attenuated in multivariate analysis, positive trends for worsening baseline oral health toward increased likelihoods of the negative outcomes were observed. Because the independent impact of oral health on geriatric outcomes could not be confirmed in our cohort, future studies in larger populations might be informative.

\section{Conclusions}

In conclusion, the results of our study showed the clinical impacts of oral health on geriatric health conditions in a prospective, longitudinal cohort of community-dwelling older adults. Rather than a mere predictor of nutritional status, oral health status can also be a geriatric parameter associated with baseline and the future burden of geriatric syndromes. More vigilance regarding the oral health status for adequate therapeutic approaches may lead to better clinical outcomes in caring for older adults at risk of frailty. In that way, it would help older adults to have healthy longer life. 


\section{Abbreviations}

ADL: Activities of daily living; ASPRA: Aging Study of Pyeongchang Rural Area; IADL: Instrumental activities of daily living; CGA: Comprehensive geriatric assessment; OR: Odds ratio; SPPB: Short Physical Performance Battery; SMI: Skeletal muscle index

\section{Supplementary Information}

The online version contains supplementary material available at https://doi. org/10.1186/s12877-021-02416-2

Additional file 1: Supplementary Table S1. The prevalence and degree of difficulty for each itemSupplementary Table S2. Baseline

characteristics according to dental prosthesis

\section{Acknowledgements}

Not applicable.

\section{Authors' contributions}

Study concept and design, J Lim, H Park, D Lee, IY Jang; data acquisition, IY Jang; data analysis and interpretation, J Lim, HW Jung; manuscript drafting, J Lim, HW Jung; critical revision of the manuscript for important intellectual content, H Park, D Lee, IY Jang; statistical analysis, J Lim, HW Jung, H Lee, E Lee; obtained funding, IY Jang; study supervision, IY Jang. The authors read and approved the final manuscript.

\section{Funding}

The Aging Study of Pyeongchang Rural Area, an intervention study, was funded by the Pyeongchang Health Center, Pyeongchang County, Gangwon Province, South Korea. This study was also supported by a grant of the Korea Health Technology R\&D Project through the Korea Health Industry Development Institute (KHIDI), funded by the Ministry of Health \& Welfare, Republic of Korea (grant number: HI18C2383), Korea Institute of Planning and Evaluation for Technology in Food, Agriculture and Forestry (IPET) through high value-added food technology development program, funded by Ministry of Agriculture, Food and Rural Affairs (MAFRA)

(321031031HD030), and the Asan Institute for Life Science, Asan Medical Center, Seoul, South Korea (2020IF0001).

\section{Availability of data and materials}

The raw data of the current study are not publicly available due to the protection of the participants personal information but are available from the corresponding author on reasonable request.

\section{Declarations}

\section{Ethics approval and consent to participate}

We analyzed records from the population-based prospective cohort, the Aging Study of Pyeongchang Rural Area (ASPRA), which was approved by the Institutional Review Board of Asan Medical Center, Seoul, Korea (2015 0673). All participants provided written informed consent. The study was conducted in accordance with approved study protocol, complying the ethical rules for human experimentation that stated in the Declaration of Helsinki.

\section{Consent for publication}

All authors have read and approved the final draft of this manuscript and agree to its submission.

\section{Competing interests}

Hee-Won Jung cofounded Dyphi Inc, a startup company developing sensor technologies on human movement and robotics. Otherwise, all authors declare that there are no potential conflicts of interest.

\section{Author details}

'Department of Gastroenterology, Asan Medical Center, University of Ulsan College of Medicine, 88 Olympic-ro 43-gil, Songpa-gu, Seoul, Republic of Korea. ${ }^{2}$ Department of Gastroenterology, Ilsan Paik Hospital, Inje University College of Medicine, Goyang, Republic of Korea. ${ }^{3}$ Divison of Pulmonary, Critical Care, and Sleep Medicine, Department of Internal Medicine,
Eunpyeong St. Mary's Hospital, College of Medicine, The Catholic University of Korea, 1021 Tongil-ro, Jingwan-dong, Eunpyeong-gu, Seoul, South Korea. ${ }^{4}$ Division of Geriatrics, Department of Internal Medicine, Asan Medical Center, University of Ulsan College of Medicine, 88 Olympic-ro 43-gil, Songpa-gu, Seoul, Republic of Korea. ${ }^{5}$ PyeongChang Health Center and County Hospital, 11 Noseong-ro, Pyeongchang-eup, Pyeongchang-gun, Gangwon-do,

Gangneung, Republic of Korea.

Received: 10 December 2020 Accepted: 4 August 2021

Published online: 04 September 2021

\section{References}

1. Gil-Montoya JA, de Mello AL, Barrios R, Gonzalez-Moles MA, Bravo M: Oral health in the elderly patient and its impact on general well-being: a nonsystematic review. Clin Interv Aging 2015, 10:461-467.

2. GBD 2017 Disease and Injury Incidence and Prevalence Collaborators: Global, regional, and national incidence, prevalence, and years lived with disability for 354 diseases and injuries for 195 countries and territories, 1990-2017: a systematic analysis for the Global Burden of Disease Study 2017. Lancet 2018, 392(10159):1789-1858.

3. Razak PA, Richard KM, Thankachan RP, Hafiz KA, Kumar KN, Sameer KM: Geriatric oral health: a review article. J Int Oral Health 2014, 6(6):110-116.

4. Peres MA, Macpherson LMD, Weyant RJ, Daly B, Venturelli R, Mathur MR, Listl S, Celeste RK, Guarnizo-Herreño CC, Kearns C et al: Oral diseases: a global public health challenge. Lancet 2019, 394(10194):249-260.

5. Astvaldsdottir A, Bostrom AM, Davidson T, Gabre P, Gahnberg L, Sandborgh Englund G, Skott P, Stahlnacke K, Tranaeus S, Wilhelmsson H et al: Oral health and dental care of older persons-A systematic map of systematic reviews. Gerodontology 2018, 35(4):290-304.

6. Hakeem FF, Bernabe E, Sabbah W: Association between oral health and frailty: A systematic review of longitudinal studies. Gerodontology 2019, 36(3):205-215

7. Torres LH, Tellez M, Hilgert JB, Hugo FN, de Sousa MD, Ismail Al: Frailty, Frailty Components, and Oral Health: A Systematic Review. J Am Geriatr Soc 2015, 63(12):2555-2562

8. Campos J, Zucoloto ML, Bonafe FSS, Maroco J: General Oral Health Assessment Index: A new evaluation proposal. Gerodontology 2017, 34(3): 334-342.

9. Cho MJ, Kim EK: Subjective chewing ability and health-related quality of life among the elderly. Gerodontology 2019, 36(2):99-106.

10. Hoogendijk EO, Afilalo J, Ensrud KE, Kowal P, Onder G, Fried LP: Frailty: implications for clinical practice and public health. Lancet 2019, 394(10206): 1365-1375.

11. Kim DH: Measuring frailty in health care databases for clinical care and research. Ann Geriatr Med Res 2020, 24(2):62-74.

12. Ramsay SE, Papachristou E, Watt RG, Tsakos G, Lennon LT, Papacosta AO, Moynihan P, Sayer AA, Whincup PH, Wannamethee SG: Influence of Poor Oral Health on Physical Frailty: A Population-Based Cohort Study of Older British Men. J Am Geriatr Soc 2018, 66(3):473-479.

13. Kidd $T$, Mold $F$, Jones $C$, Ream $E$, Grosvenor $W$, Sund-Levander $M$, Tingström $P$, Carey $\mathrm{N}$ : What are the most effective interventions to improve physical performance in pre-frail and frail adults? A systematic review of randomised control trials. BMC Geriatr 2019, 19(1):184

14. Chan DC, Tsou HH, Yang RS, Tsauo JY, Chen CY, Hsiung CA, Kuo KN: A pilot randomized controlled trial to improve geriatric frailty. BMC Geriatr 2012, 12(1):58.

15. Romera L, Orfila F, Segura JM, Ramirez A, Möller M, Fabra ML, Lancho S, Bastida N, Foz G, Fabregat MA et al: Effectiveness of a primary care based multifactorial intervention to improve frailty parameters in the elderly: a randomised clinical trial: rationale and study design. BMC Geriatr 2014, 14(1): 125.

16. Jung HW, Jang IY, Lee YS, Lee CK, Cho El, Kang WY, Chae JH, Lee EJ, Kim $\mathrm{DH}$ : Prevalence of frailty and aging-related health conditions in older koreans in rural communities: a cross-sectional analysis of the aging study of Pyeongchang rural area. J Korean Med Sci 2016, 31(3):345-352.

17. Jang SN, Kawachi I: Why do older Korean adults respond differently to activities of daily living and instrumental activities of daily living? A differential item functioning analysis. Ann Geriatr Med Res 2019, 23(4):197203.

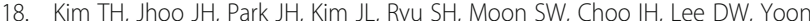
JC, Do YJ et al: Korean version of mini mental status examination for 
dementia screening and its' short form. Psychiatry Investig 2010, 7(2):102108.

19. Cho MJ, Kim KH: Use of the center for epidemiologic studies depression (CES-D) scale in Korea. J Nerv Ment Dis 1998, 186(5):304-310.

20. Rubenstein LZ, Harker JO, Salvà A, Guigoz Y, Vellas B: Screening for undernutrition in geriatric practice: developing the short-form mininutritional assessment (MNA-SF). J Gerontol A Biol Sci Med Sci 2001, 56(6): M366-372.

21. Guralnik JM, Simonsick EM, Ferrucci L, Glynn RJ, Berkman LF, Blazer DG, Scherr PA, Wallace RB: A short physical performance battery assessing lower extremity function: association with self-reported disability and prediction of mortality and nursing home admission. J Gerontol 1994, 49(2):M85-94.

22. Chen LK, Woo J, Assantachai P, Auyeung TW, Chou MY, lijima K, Jang HC, Kang L, Kim M, Kim S et al: Asian Working Group for Sarcopenia: 2019 consensus update on sarcopenia diagnosis and treatment. J Am Med Dir Assoc 2020, 21(3):300-307 e302.

23. Shim H, Kim S, Kim M, Kim BS, Jeong E, Lee YJ, Won CW: Older men living with spouse and older women living with spouse and children have lower frailty prevalence: the Korean Frailty and Aging Cohort Study (KFACS). Ann Geriatr Med Res 2020, 24(3):204-210.

24. Searle SD, Mitnitski A, Gahbauer EA, Gill TM, Rockwood K: A standard procedure for creating a frailty index. BMC Geriatr 2008, 8(1):24.

25. Jang I-Y, Jung H-W, Lee CK, Lee YS, Lee E, Kim DH: Comparison between Korean version of Physical Activity Scale for the elderly and International Physical Activity Questionnaire-Short Form in evaluation of frailty phenotype. Ann Geriatr Med Res 2017, 21(3):101-107.

26. Chen S, Honda T, Chen T, Narazaki K, Haeuchi Y, Supartini A, Kumagai S: Screening for frailty phenotype with objectively-measured physical activity in a west Japanese suburban community: evidence from the Sasaguri Genkimon Study. BMC Geriatr 2015, 15:36.

27. Toniazzo MP, Amorim PS, Muniz F, Weidlich P: Relationship of nutritional status and oral health in elderly: systematic review with meta-analysis. Clin Nutr 2018, 37(3):824-830.

28. van der Pols-Vijlbrief R, Wijnhoven HA, Schaap LA, Terwee CB, Visser M: Determinants of protein-energy malnutrition in community-dwelling older adults: a systematic review of observational studies. Ageing Res Rev 2014, 18:112-131.

29. Wright L, Cotter D, Hickson M, Frost G: Comparison of energy and protein intakes of older people consuming a texture modified diet with a normal hospital diet. J Hum Nutr Diet 2005, 18(3):213-219.

30. Ship JA: Diabetes and oral health: an overview. J Am Dent Assoc 2003, 134 Suppl 1:4S-10S.

31. Beck JD, Slade G, Offenbacher S: Oral disease, cardiovascular disease and systemic inflammation. Periodontol 2000 2000, 23(1):110-120.

32. Paju S, Scannapieco FA: Oral biofilms, periodontitis, and pulmonary infections. Oral Dis 2007, 13(6):508-512.

33. Ruospo M, Palmer SC, Craig JC, Gentile G, Johnson DW, Ford PJ, Tonelli M, Petruzzi M, De Benedittis M, Strippoli GF: Prevalence and severity of oral disease in adults with chronic kidney disease: a systematic review of observational studies. Nephrol Dial Transplant 2014, 29(2):364-375.

34. Syrjälä AM, Ylöstalo P, Ruoppi P, Komulainen K, Hartikainen S, Sulkava R, Knuuttila M: Dementia and oral health among subjects aged 75 years or older. Gerodontology 2012, 29(1):36-42.

35. Oral health [https://www.who.int/news-room/fact-sheets/detail/oral-health].

36. Cademartori MG, Gastal MT, Nascimento GG, Demarco FF, Corrêa MB: Is depression associated with oral health outcomes in adults and elders? A systematic review and meta-analysis. Clin Oral Investig 2018, 22(8):26852702.

37. Hayashi K, Izumi M, Mastuda Y, Isobe A, Akifusa S: Relationship between anxiety/depression and oral health-related quality of life in inpatients of convalescent hospitals. Odontology 2019, 107(2):254-260.

38. Jang IY, Jung HW, Lee HY, Park H, Lee E, Kim DH: Evaluation of clinically meaningful changes in measures of frailty. J Gerontol A Biol Sci Med Sci 2020, 75(6):1143-1147

39. Won CW: Frailty: its scope and implications for geriatricians. Ann Geriatr Med Res 2019, 23(3):95-97.

40. Jang $I Y$, Lee E, Lee H, Park H, Kim S, Kim Kl, Jung HW, Kim DH: Characteristics of sarcopenia by European consensuses and a phenotype score. J Cachexia Sarcopenia Muscle 2020, 11(2):497-504.
41. Sheiham A, Steele JG, Marcenes W, Lowe C, Finch S, Bates CJ, Prentice A, Walls AW: The relationship among dental status, nutrient intake, and nutritional status in older people. J Dent Res 2001, 80(2):408-413.

42. Otomo-Corgel J, Pucher JJ, Rethman MP, Reynolds MA: State of the science: chronic periodontitis and systemic health. J Evid Based Dent Pract 2012, 12(3 Suppl):20-28.

43. Kandelman D, Petersen PE, Ueda H: Oral health, general health, and quality of life in older people. Special Care in Dentistry 2008, 28(6):224-236.

44. Castrejon-Perez RC, Borges-Yanez SA, Gutierrez-Robledo LM, Avila-Funes JA: Oral health conditions and frailty in Mexican community-dwelling elderly: a cross sectional analysis. BMC Public Health 2012, 12:773.

45. Rockwood K, Song X, MacKnight C, Bergman H, Hogan DB, McDowell I, Mitnitski A: A global clinical measure of fitness and frailty in elderly people. CMAJ 2005, 173(5):489-495.

46. Park CM, Oh G, Lee H, Jung HW, Lee E, Jang IY, Kim DH: Multicomponent intervention and long-term disability in older adults: a nonrandomized prospective study. In: J Am Geriatr Soc. 2020/11/07 edn; 2020.

47. Jang IY, Jung HW, Park H, Lee CK, Yu SS, Lee YS, Lee E, Glynn RJ, Kim DH: A multicomponent frailty intervention for socioeconomically vulnerable older adults: a designed-delay study. Clin Interv Aging 2018, 13:1799-1814.

\section{Publisher's Note}

Springer Nature remains neutral with regard to jurisdictional claims in published maps and institutional affiliations.

\section{Ready to submit your research? Choose BMC and benefit from:}

- fast, convenient online submission

- thorough peer review by experienced researchers in your field

- rapid publication on acceptance

- support for research data, including large and complex data types

- gold Open Access which fosters wider collaboration and increased citations

- maximum visibility for your research: over $100 \mathrm{M}$ website views per year

At $\mathrm{BMC}$, research is always in progress.

Learn more biomedcentral.com/submissions 